\title{
Accumulation of CTCF-binding sites drives expression divergence between tandemly duplicated genes in humans
}

\author{
Ben-Yang Liao*, Andrew Ying-Fei Chang \\ From The Twelfth Asia Pacific Bioinformatics Conference (APBC 2014) \\ Shanghai, China. 17-19 January 2014
}

\begin{abstract}
Background: During eukaryotic genome evolution, tandem gene duplication is the most frequent event giving rise to clustered gene families. However, how expression divergence between tandemly duplicated genes has emerged and maintained remain unclear. In particular, it is unknown if epigenetic regulators have been involved in the process.

Results: We demonstrate that CCCTC-binding factor (CTCF), the master epigenetic regulator and the only known insulator protein in humans, has played a predominant role in generating divergence in both expression profiles and expression levels between adjacent paralogs in the human genome. This phenomenon was not observed for non-paralogous adjacent genes. After tandem duplication events, CTCF-binding sites gradually accumulate between paralogs. This trend was more prominent for genes involved in particular functions.

Conclusions: The accumulation of CTCF-binding sites drives expression divergence of tandemly duplicated genes. This process is likely targeted by natural selection. Our study reveals the importance of CTCF to the evolution of animal diversity and complexity.
\end{abstract}

\section{Background}

Gene duplication is a major driver for the emergence of organismal complexity and evolutionary innovations $[1,2]$. Tandem duplication is the most common route to the formation of clustered paralogous genes $[3,4]$. A newly duplicated gene must diverge from its progenitor gene in coding sequence or expression, or it will degenerate due to redundancy $[1,5,6]$. To acquire novel transcription patterns, tandemly duplicated genes need to interrupt expression similarity due to shared upstream cis-elements upon origin [3,7] and transcriptional interference contributed by physical proximity [8]. Despite the challenges, functionally important gene clusters consisting of paralogs with distinct expression patterns are found in a wide range of species, including human $[9,10]$. Therefore, it is important to understand the

Division of Biostatistics \& Bioinformatics, Institute of Population Health Sciences, National Health Research Institutes, Zhunan, Miaoli County 350, Taiwan, R.O.C 
transcriptional interference [8]. Using RNA-seq data from six human adult tissues [20], we measured gene expression dissimilarity between adjacent genes in terms of expression profile or expression level using $E x p D_{1-r}$ or $E x p D_{\text {Euc }}$ (see Methods), respectively. $E x p D_{1-r}$ focused on changes in the shape across the tissue dimension, while $\operatorname{Exp} D_{\text {Euc }}$ focused on summed changes in abundance. We studied divergences in both profiles and abundances because previous studies have shown that the observations from the two aspects did not necessarily produce consistent results [21], possibly due to different underlying mechanisms controlling the properties [22].

Mammalian genes close to each other have similar expression profiles $[8,19]$. CTCF-binding sites can prevent undesirable crosstalk between active and inactive genomic regions [23]. DNA methylation upstream of a gene can inhibit its transcriptional initiation [24]. To determine if the effect of intergenic distance, the number of CTCF-binding sites, and DNA methylation is related to shared evolutionary origin, we measured $E x p D_{1-r}$ and $E x p D_{\text {Euc }}$ in non-paralogous adjacent genes. Non-paralogous gene pairs with a longer intergenic distance $(d$, calculated as the distance in nucleotides between the transcriptional start sites, TSS), more overlapping CTCF-binding sites (\#CTCF, see Methods), or a larger difference in upstream DNA methylation $\left(\triangle C p G_{\mathrm{O} / \mathrm{E}}\right.$, see Methods) had greater $\operatorname{Exp} D_{1-\mathrm{r}}$ or $\operatorname{Exp} D_{\mathrm{Euc}}$ (see $\rho$ in Table 1). Although $d$, \#CTCF, and $\triangle C p G_{\mathrm{O} / \mathrm{E}}$ were interrelated ( $d$ vs. \#CTCF: $\rho=0.521, P<10^{-300}$; $\# C T C F$ vs. $\triangle C p G_{\mathrm{O} / \mathrm{E}}: \rho=0.075, P<10^{-40} ; \Delta C p G_{\mathrm{O} / \mathrm{E}}$ vs. $d$ : $\rho=0.166, P<10^{-192}$ ), partial correlation analyses (see Methods) suggested that the effects of $d$, \#CTCF, and $\Delta C p G_{\mathrm{O} / \mathrm{E}}$ on generating expression dissimilarity between adjacent genes was independent. $d$ had the largest direct influence on $\operatorname{Exp}_{1-\mathrm{r} \text {, and }} \triangle C p G_{\mathrm{O} / \mathrm{E}}$ had the largest direct influence on $\operatorname{Exp} D_{\text {Euc. }}$ \#CTCF had a weak but significant effect on $E x p D_{1-r}$ and an intermediate effect on $\operatorname{Exp} D_{\text {Euc }}$ (see $\rho_{\mathrm{p}}$ in Table 1). Although CTCF binding can vary among cell types [25], when we define \#CTCF using joint CTCF ChIP-seq peaks (see Methods) instead of overlapping CTCF peaks, the results did not change (Table S1 in Additional file 1).
Mechanisms generating coding sequence divergence, such as change in protein structure or splicing, between paralogous genes have been intensively investigated [2,26-28]. By contrast, mechanisms generating expression divergence have garnered less attention. Although \#CTCF was not the strongest determinant of expression divergence in non-paralogous adjacent gene pairs (Table 1), for adjacent paralogs, \#CTCF had the greatest direct influence on $E x p D_{1-\mathrm{r}}$ and $\operatorname{Exp} D_{\mathrm{Euc}}$, followed by $\triangle C p G_{\mathrm{O} / \mathrm{E}}$ (see $\rho_{\mathrm{p}}$ in Table 2). Repeating analysis based on an independently generated and unpublished RNA-seq dataset including 16 human tissues (Illumina BodyMap 2.0 project, see Methods) produced a result consistent with Table 1 and 2 (Table S2 in Additional file 1), suggesting the robustness of the pattern found.

We classified adjacent paralogs into three groups according the orientations: head-to-head, head-to-tail and tail-to-tail [29]. Although reduced sample sizes resulted in reduced statistical significance, the pattern of the greatest impact \#CTCF on expression divergences held regardless of the orientation of paralogs (Table 3). Using microarray expression data, a previous study found that intergenic distance was related to expression divergence for tandemly arrayed paralogs [30]. However, microarray data is known to have cross-hybridization related biases [17], and we found no direct association between intergenic distance and expression divergence for tandemly arrayed paralogs after controlling for $\# C T C F$ and $\triangle C p G_{\mathrm{O} / \mathrm{E}}$ (see $\rho_{\mathrm{p}}$ of $d$ vs. $\operatorname{Exp} D_{1-\mathrm{r}}$ or $E x p D_{\text {Euc }}$, Table 2). Taken together, these results suggest that CTCF-binding sites play a very significant, if not primary, role in driving expression divergence of tandemly duplicated genes.

There are two hypotheses to explain the influence of CTCF-binding sites in driving expression divergence of tandem paralogs. First, tandem paralogs that arose in genomic regions with high densities of CTCF-binding sites nearby are more likely to be preserved due to immediate independence of gene regulation. Second, CTCF-binding sites accumulated over time to enhance independent gene regulation of tandem paralogs, especially those have been functionally diverged. If the first

Table 1 Rank correlations $(\rho)$ and partial rank correlations $\left(\rho_{p}\right)$ of the genomic properties with expression dissimilarities (measured by $\operatorname{Exp}_{1-\mathrm{r}}$ or $\operatorname{Exp} D_{\text {Euc }}$ ) of the non-paralogous adjacent genes

\begin{tabular}{|c|c|c|c|c|}
\hline \multirow[t]{2}{*}{ Genomic properties $^{a}$} & \multicolumn{2}{|c|}{$\operatorname{Exp}_{1-\mathrm{r}}$} & \multicolumn{2}{|c|}{$\operatorname{Exp} D_{\text {Euc }}$} \\
\hline & $\rho{\text { (P-value })^{b}}^{b}$ & $\rho_{\mathrm{p}}(P \text {-value })^{b, c}$ & $\rho{\text { (P-value })^{b}}^{b}$ & $\rho_{\mathrm{p}}(P \text {-value })^{b, c}$ \\
\hline $\bar{d}$ & $0.180\left(<10^{-217}\right)$ & $0.130\left(<10^{-113}\right)$ & $0.112\left(<10^{-83}\right)$ & $0.040\left(<10^{-11}\right)$ \\
\hline \#CTCF & $0.120\left(<10^{-98}\right)$ & $0.032\left(<10^{-7}\right)$ & $0.104\left(<10^{-72}\right)$ & $0.058\left(<10^{-22}\right)$ \\
\hline$\Delta C p G_{\mathrm{O} / \mathrm{E}}$ & $0.077\left(<10^{-39}\right)$ & $0.049\left(<10^{-16}\right)$ & $0.196\left(<10^{-258}\right)$ & $0.182\left(<10^{-227}\right)$ \\
\hline
\end{tabular}

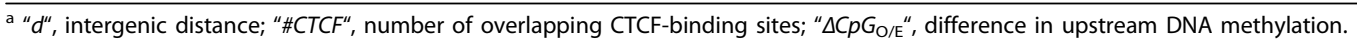

${ }^{b} P$ values show the probabilities of the observations under the hypothesis of no correlation.

c Spearman's partial correlation coefficient $\rho_{p}$ is computed by controlling for the other two genomic properties listed in ${ }^{a}$ 
Table 2 Rank correlations $(\rho)$ and partial rank correlations $\left(\rho_{p}\right)$ of the examined genomic properties with expression dissimilarities (measured by $\operatorname{Exp}_{1-\mathrm{r}}$ or $\operatorname{Exp} D_{\mathrm{Euc}}$ ) of the paralogous adjacent genes

\begin{tabular}{lcccc}
\hline Genomic properties $^{\mathbf{a}}$ & \multicolumn{3}{c}{ ExpD $_{\text {1-r }}$} & \multicolumn{2}{c}{${\text { Exp } D_{\text {Euc }}}$} \\
\cline { 2 - 5 } & $\boldsymbol{\rho}(\boldsymbol{P} \text {-value })^{\mathbf{b}}$ & $\boldsymbol{\rho}_{\mathbf{p}}$ (P-value) $^{\mathbf{b}, \mathbf{c}}$ & $\boldsymbol{\rho}(\boldsymbol{P} \text {-value })^{\mathbf{b}}$ & $\boldsymbol{\rho}_{\mathbf{p}}(\boldsymbol{P} \text {-value })^{\mathbf{b}, \mathbf{c}}$ \\
\hline$d$ & $0.039(0.164)$ & $-0.011(0.707)$ & $0.100\left(<10^{-3}\right)$ & $0.021(0.461)$ \\
$\# C T C F$ & $0.111\left(<10^{-4}\right)$ & $0.103\left(<10^{-3}\right)$ & $0.187\left(<10^{-10}\right)$ & $0.159\left(<10^{-7}\right)$ \\
$\triangle C P G_{\text {O/E }}$ & $0.069(0.015)$ & $0.054(0.023)$ & $0.102\left(<10^{-3}\right)$ & $0.094\left(<10^{-3}\right)$ \\
\hline
\end{tabular}

a " $d$ ", intergenic distance; "\#CTCF", number of overlapping CTCF-binding sites; " $\triangle C p G_{\mathrm{O} / \mathrm{E}}$ ", difference in upstream DNA methylation.

${ }^{b} P$ values show the probabilities of the observations under the hypothesis of no correlation.

' Spearman's partial correlation coefficient $\rho_{p}$ is computed by controlling for the other two genomic properties listed in ${ }^{\text {a }}$

hypothesis is correct, there would be no correlation between the divergence time of paralogs (measured by $d_{\mathrm{S}}$ or $T_{\mathrm{phy}}$, see Methods) and \#CTCF. However, we observed a positive correlation between $d_{\mathrm{S}}$ or $T_{\mathrm{phy}}$ and \#CTCF (Table 4), suggesting that the second hypothesis is correct. \#CTCF had stronger rank correlation $(\rho)$, which is positive, to $d_{\mathrm{S}}$ (or $T_{\text {phy }}$ ) than $d$ and $\Delta C p G_{\mathrm{O} / \mathrm{E}}$ (Table 4). Partial correlation analyses further suggested that the increase of \#CTCF with $d_{\mathrm{S}}$ (or $T_{\text {phy }}$ ) is not caused by the change in $d$ or $\Delta C p G_{\mathrm{O} / \mathrm{E}}$ or their combined effect over time (see $\rho_{\mathrm{p}}$ in Table 4). By contrast, the insignificant partial correlation of $d$ with respect to $d_{\mathrm{S}}$ (or $T_{\text {phy }}$ ) indicated that the increase $d$ over time can be explained by the increase in the number of CTCFbinding sites and the associated changes in DNA methylation.

To determine whether tandem paralogs with specific functions tend to have a greater number of intervening CTCF-binding sites, we performed enrichment analyses in Gene Ontology (GO) terms. To eliminate the potential effect of duplicability in GO analysis [4], paralogous and non-paralogous gene pairs were analyzed separately.
To control for the potential effect of gene density [31], $\# C T C F / d$ was used instead of \#CTCF (although using \#CTCF produced a consistent result, which is not shown). Gene pairs in the top quartile of CTCF-binding site density (\#CTCF/d) were compared against the bottom three quartiles. Enriched/depleted GO terms for the paralog group were substantially different from those in the non-paralog group (Table 5). Only two GO terms (GO:0010033, response to organic substance; GO:0031012, extracellular matrix) had the same enrichment status ("enriched") in both groups. Tandemly duplicated genes with a higher density of intervening CTCF-binding sites tended to specifically encode proteins involved in gene expression (GO:0010467, GO:0008134), metabolic processes (GO:0019222, GO:0006139, GO:0050790), or cellular processes (GO:0050794, GO:0051128, GO:0044249) through DNA binding (GO:0003677), SMAD binding (GO:0046332), growth factor binding (GO:0019955), or kinase interaction (GO:0019210, GO:0019887) in receptor complexes (GO:0043235) or intracellular regions (GO:0031012) (Table 5). This result implied that the densities of CTCF

Table 3 Rank correlations $(\rho)$ and partial rank correlations $\left(\rho_{p}\right)$ of the examined genomic properties with expression dissimilarities (measured by $\operatorname{Exp} D_{1-\mathrm{r}}$ or $\operatorname{Exp} D_{\text {Euc }}$ ) of the adjacent paralogous genes of different orientations.

\begin{tabular}{|c|c|c|c|c|}
\hline \multirow[t]{2}{*}{ Genomic properties $^{a}$} & \multicolumn{2}{|c|}{$\operatorname{ExpD}_{1-\mathrm{r}}$} & \multicolumn{2}{|c|}{$\operatorname{Exp}_{\mathrm{Euc}}$} \\
\hline & $\rho{\text { (P-value })^{b}}^{b}$ & $\rho_{p}(P \text {-value })^{b, c}$ & $\rho{\text { (P-value })^{b}}^{b}$ & $\rho_{p}(P \text {-value })^{b, c}$ \\
\hline \multicolumn{5}{|l|}{ Head-to-Head $^{d}$} \\
\hline$d$ & $0.165(0.072)$ & $0.106(0.250)$ & $0.150(0.109)$ & $0.036(0.700)$ \\
\hline$\# C T C F$ & $0.213(0.020)$ & $0.173(0.058)$ & $0.352\left(<10^{-4}\right)$ & $0.327\left(<10^{-3}\right)$ \\
\hline$\Delta C p G_{O / E}$ & $-0.024(0.794)$ & $0.001(0.991)$ & $-0.071(0.443)$ & $-0.054(0.561)$ \\
\hline \multicolumn{5}{|l|}{ Head-to-Tail ${ }^{d}$} \\
\hline$d$ & $0.005(0.870)$ & $-0.050(0.110)$ & $0.089\left(<10^{-2}\right)$ & $0.016(0.607)$ \\
\hline$\# C T C F$ & $0.100\left(<10^{-2}\right)$ & $0.110\left(<10^{-3}\right)$ & $0.151\left(<10^{-5}\right)$ & $0.127\left(<10^{-4}\right)$ \\
\hline$\Delta C p G_{O / E}$ & $0.083\left(<10^{-2}\right)$ & $0.085\left(<10^{-2}\right)$ & $0.109\left(<10^{-3}\right)$ & $0.104\left(<10^{-3}\right)$ \\
\hline \multicolumn{5}{|l|}{ Tail-to-Tail $^{d}$} \\
\hline$d$ & $0.139(0.110)$ & $0.105(0.230)$ & $0.145(0.096)$ & $0.046(0.602)$ \\
\hline$\# C T C F$ & $0.113(0.195)$ & $0.061(0.482)$ & $0.271\left(<10^{-2}\right)$ & $0.202(0.019)$ \\
\hline$\triangle C p G_{O / E}$ & $0.050(0.569)$ & $0.018(0.0835)$ & $0.212(0.014)$ & $0.153(0.078)$ \\
\hline
\end{tabular}

a " $d$ ", intergenic distance; "\#CTCF", number of overlapping CTCF-binding sites; " $\triangle C p G_{O / E}$ ", difference in upstream DNA methylation.

${ }^{\mathrm{b}} P$ values show the probabilities of the observations under the hypothesis of no correlation.

' Spearman's partial correlation coefficient $\rho_{p}$ is computed by controlling for the other two genomic properties listed in ${ }^{\text {a }}$

${ }^{d}$ There were 120, 1003 and 133 head-to-head, head-to-tail and tail-to-tail adjacent paralogs, respectively. 
Table 4 Rank correlations $(\rho)$ and partial rank correlations $\left(\rho_{p}\right)$ of the examined genomic properties with the divergence time of the paralogous adjacent genes.

\begin{tabular}{|c|c|c|c|c|}
\hline \multirow[t]{2}{*}{ Genomic properties $^{a}$} & \multicolumn{2}{|c|}{$d_{\mathrm{s}}$} & \multicolumn{2}{|c|}{$T_{\text {phy }}$} \\
\hline & $\rho{\text { (P-value })^{b}}^{b}$ & $\rho_{\mathrm{p}}(P \text {-value })^{b, c}$ & $\rho{\text { (P-value })^{b}}^{b}$ & $\rho_{p}(P \text {-value })^{b, c}$ \\
\hline \multicolumn{5}{|l|}{ All adjacent paralogs } \\
\hline$d$ & $0.138\left(<10^{-5}\right)$ & $0.057(0.056)$ & $0.141\left(<10^{-6}\right)$ & $0.053(0.060)$ \\
\hline$\# C T C F$ & $0.225\left(<10^{-13}\right)$ & $0.189\left(<10^{-9}\right)$ & $0.219\left(<10^{-14}\right)$ & $0.178\left(<10^{-9}\right)$ \\
\hline$\Delta C p G_{O / E}$ & $0.097\left(<10^{-2}\right)$ & $0.089\left(<10^{-2}\right)$ & $0.084\left(<10^{-2}\right)$ & $0.073\left(<10^{-2}\right)$ \\
\hline \multicolumn{5}{|c|}{ Adjacent paralogs associated with GO terms in which high \#CTCF/d genes were specifically enriched } \\
\hline$d$ & $0.086(0.152)$ & $-0.070(0.245)$ & $0.108(0.072)$ & $-0.038(0.526)$ \\
\hline \#CTCF & $0.292\left(<10^{-6}\right)$ & $0.276\left(<10^{-5}\right)$ & $0.273\left(<10^{-5}\right)$ & $0.243\left(<10^{-4}\right)$ \\
\hline$\triangle C p G_{O / E}$ & $0.122(0.043)$ & $0.079(0.186)$ & $0.132(0.027)$ & $0.092(0.125)$ \\
\hline
\end{tabular}

a " $d$ ", intergenic distance; "\#CTCF", number of overlapping CTCF-binding sites; " $\triangle C p G_{O / E}$ ", difference in upstream DNA methylation.

${ }^{b} P$ values show the probabilities of the observations under the hypothesis of no correlation.

' Spearman's partial correlation coefficient $\rho_{p}$ is computed by controlling for the other two genomic properties listed in ${ }^{\text {a }}$

binding sites between tandem paralogs were not contributed by the genomic background.

Genomic regions of high densities of CTCF binding sites can emerge through stochastic evolutionary processes. To examine if high CTCF-binding site density between tandem duplicates is the outcome of gradual CTCF-binding site accumulation by natural selection, we focused on the subset of 278 paralogous pairs in which at least one paralog had one of the abovementioned enriched GO categories. In this subset of tandem paralogs, $\rho_{\mathrm{p}}$ of \#CTCF vs. $d_{\mathrm{S}}$ (or $T_{\mathrm{phy}}$ ) after controlling for $d$ and $\triangle C p G_{\mathrm{O} / \mathrm{E}}$ was stronger (\#CTCF vs. $d_{\mathrm{S}}$ : $\rho_{\mathrm{p}}=0.276, P<10^{-5}$; \#CTCF vs. $T_{\text {phy }}: \rho_{\mathrm{p}}=0.243, P<10^{-4}$ ) than that observed in the full set of adjacent paralogs (\#CTCF vs. $d_{\mathrm{S}}: \rho_{\mathrm{p}}=0.189, P<10^{-9}$; \#CTCF vs. $T_{\mathrm{phy}}$ : $\rho_{\mathrm{p}}=0.178, P<10^{-9}$ ) (Table 4). When \#CTCF was defined by joint CTCF ChIP-seq peaks rather than overlapping CTCF peaks, the results were similar (Table S3 in Additional file 1). Therefore, the trend to accumulate CTCFbinding sites following a tandem duplication event resulted in more CTCF-binding sites (both absolute number and density) between paralogs, especially for those with enriched GO-categories shown in Table 5.

\section{Conclusions}

Combining human genomic and transcriptomic data, this study demonstrates that CTCF and its binding sites play a major role driving the expression evolution of tandemly duplicated genes. Following tandem duplication events, CTCF-binding sites gradually accumulate between the paralogs to increase their divergences in expression profile and their divergences in expression level. The role of CTCF-binding sites is not limited to the insulation of DNA methylation domains, because the effects of \#CTCF on $\operatorname{Exp} D_{1-\mathrm{r}}$ (or $\operatorname{Exp} D_{\mathrm{Euc}}$ ) were still significant even after controlling for $\triangle C p G_{\mathrm{O} / \mathrm{E}}$ (Table 2). Thus, CTCF, a conserved regulatory protein [32], affects the expression evolution of adjacent genes in genomes from flies [33] to humans and is important for the evolution of organismal complexity in animals.

\section{Methods}

Annotation of the human genome (Ensembl v72), including gene coordinates, TSS, and paralog divergence, was retrieved through BioMart (http://www.biomart.org/) [34]. Orientation for each paralogous pair (head-to-head, head-to-tail, or tail-to-tail) was determined using strand information. For each paralogous pair, the rate of synonymous changes $\left(d_{\mathrm{S}}\right)$ was calculated using PAML [35], and the phylogenetic age $\left(T_{\text {phy }}\right)$ was assigned according to Table S4 in Additional file 1 based on Ensembl's annotation of the most recent common ancestor [36]. A smaller $d_{\mathrm{S}}$ or $T_{\text {phy }}$ indicated a more recent divergence time. The RNA-seq-based gene expression signals in the human brain, cerebellum, heart, kidney, liver and testis (GSE30352) [20] were obtained from NCBI Gene Expression Omnibus (GEO) (http://www.ncbi.nlm.nih.gov/geo/ ). The raw reads of RNA-seq data in 16 human tissues (adipose, adrenal, brain, breast, colon, heart, kidney, liver, lung, lymph node, ovary, prostate, skeletal muscle, testes, thyroid, white blood cells) by Illumina BodyMap 2.0 project were downloaded from GSE30611 of GEO and were processed following our previous studies $[17,37]$ to obtain expression signals. Upstream DNA methylation for a gene was calculated based on the 500 nucleotides upstream of the TSS by $\mathrm{CpG}_{\mathrm{O} / \mathrm{E}}=P_{\mathrm{CpG}} /\left(P_{\mathrm{C}} \times P_{\mathrm{G}}\right)$, where $P_{\mathrm{CpG}}, P_{\mathrm{C}}$, and $P_{\mathrm{G}}$ are the frequencies of $\mathrm{CpG}$ dinucleotides, $\mathrm{C}$ nucleotides, and $\mathrm{G}$ nucleotides, respectively $[17,38]$. The difference in upstream DNA methylation, $\Delta C p G_{\mathrm{O} / \mathrm{E}}$, was calculated by the absolute value of the difference in $\mathrm{CpG}_{\mathrm{O} / \mathrm{E}}$ between the two adjacent genes compared. In total, we obtained 30,164 non-paralogous and 1,256 paralogous gene pairs based on 32,164 human genes with detectable expression and estimable $\mathrm{CpG}_{\mathrm{O} / \mathrm{E}}$. 
Table 5 Enriched/depleted GO terms at level 4 for genes with high \#CTCF/d flanking regions

\begin{tabular}{|c|c|c|}
\hline \multirow[t]{2}{*}{$\begin{array}{l}\text { Functional } \\
\text { categories }\end{array}$} & Duplicate with $25 \%$ top \#CTCF/d vs. rest of duplicates & $\begin{array}{l}\text { Non-duplicates with } 25 \% \text { top \#CTCF/d vs. } \\
\text { rest of non-duplicates }\end{array}$ \\
\hline & GO terms ${ }^{a}\left(\uparrow\right.$ or $\downarrow^{b}, P$-value $\left.{ }^{c}\right)$ & GO terms $\left(\uparrow\right.$ or $\downarrow^{b}, P$-value $\left.{ }^{c}\right)$ \\
\hline \multicolumn{3}{|c|}{ Molecular functions } \\
\hline & $\begin{array}{l}\text { DNA binding } \\
(\mathrm{GO}: 0003677)(\uparrow, P<0.05)\end{array}$ & $\begin{array}{l}\text { transferase activity, transferring phosphorus-containing groups } \\
(\mathrm{GO}: 0016772)\left(\uparrow, P<10^{-7}\right)\end{array}$ \\
\hline & $\begin{array}{l}\text { transcription factor binding } \\
(\mathrm{GO}: 0008134)\left(\uparrow, P<10^{-2}\right)\end{array}$ & $\begin{array}{l}\text { hydrolase activity, acting on acid anhydrides (GO:0016817) } \\
\left(\uparrow, P<10^{-4}\right)\end{array}$ \\
\hline & $\begin{array}{l}\text { SMAD binding } \\
(G 0: 0046332)(\uparrow, P<0.05)\end{array}$ & $\begin{array}{l}\text { protein domain specific binding } \\
(\mathrm{GO}: 0019904)\left(\uparrow, P<10^{-2}\right)\end{array}$ \\
\hline & $\begin{array}{l}\text { growth factor binding } \\
(\mathrm{GO} 00019838)(\uparrow, P<0.05)\end{array}$ & $\begin{array}{l}\text { substrate-specific transmembrane transporter activity } \\
(G O: 0022891)\left(\uparrow, P<10^{-4}\right)\end{array}$ \\
\hline & $\begin{array}{l}\text { kinase inhibitor activity } \\
(\mathrm{GO}: 0019210)(\uparrow, P<0.05)\end{array}$ & $\begin{array}{l}\text { cytoskeletal protein binding } \\
(\mathrm{GO}: 0008092)\left(\uparrow, P<10^{-7}\right)\end{array}$ \\
\hline & $\begin{array}{l}\text { peptidase inhibitor activity } \\
(\mathrm{GO}: 0030414)(\uparrow, P<0.05)\end{array}$ & $\begin{array}{l}\text { phospholipid binding } \\
(\mathrm{GO}: 0005543)\left(\uparrow, P<10^{-2}\right)\end{array}$ \\
\hline & $\begin{array}{l}\text { protein kinase regulator activity } \\
(\mathrm{GO}: 0019887)(\uparrow, P<0.05)\end{array}$ & $\begin{array}{l}\text { identical protein binding } \\
(\mathrm{GO}: 0042802)\left(\uparrow, P<10^{-8}\right)\end{array}$ \\
\hline & $\begin{array}{l}\text { transferase activity, transferring acyl groups } \\
(\mathrm{GO}: 0016746)(\uparrow, P<0.05)\end{array}$ & $\begin{array}{l}\text { receptor binding } \\
(\mathrm{GO}: 0005102)\left(\uparrow, P<10^{-9}\right)\end{array}$ \\
\hline & $\begin{array}{l}\text { transferase activity, transferring glycosyl groups } \\
(\mathrm{GO}: 0016757)(\downarrow, P<0.05)\end{array}$ & $\begin{array}{l}\text { heat shock protein binding } \\
(\mathrm{GO}: 0031072)(\uparrow, P<0.05)\end{array}$ \\
\hline & $\begin{array}{l}\text { monooxygenase activity } \\
(\mathrm{GO}: 0004497)(\downarrow, P<0.05)\end{array}$ & $\begin{array}{l}\text { oxidoreductase activity, acting on peroxide as acceptor } \\
(\mathrm{GO}: 0016684)\left(\uparrow, P<10^{-2}\right)\end{array}$ \\
\hline \multicolumn{3}{|c|}{ Cellular components } \\
\hline & $\begin{array}{l}\text { extracellular matrix } \\
(\mathrm{GO}: 0031012)\left(\uparrow, P<10^{-6}\right)\end{array}$ & $\begin{array}{l}\text { extracellular matrix } \\
(\mathrm{GO}: 0031012)\left(\uparrow, P<10^{-3}\right)\end{array}$ \\
\hline & $\begin{array}{l}\text { intracellular } \\
(\mathrm{GO}: 0031012)(\uparrow, P<0.05)\end{array}$ & $\begin{array}{l}\text { extracelluar space } \\
(\mathrm{GO}: 0005615)\left(\uparrow, P<10^{-8}\right)\end{array}$ \\
\hline & receptor complex (GO:0043235) $(\uparrow, P<0.05)$ & $\begin{array}{l}\text { endomembrane system } \\
(\mathrm{GO}: 0012505)\left(\uparrow, P<10^{-3}\right)\end{array}$ \\
\hline & & membrane-bounded vesicle (GO:0031988) $(\uparrow, P<0.05)$ \\
\hline & & $\begin{array}{l}\text { cell surface } \\
\text { (GO:0009986) }\left(\uparrow, P<10^{-4}\right)\end{array}$ \\
\hline & & $\begin{array}{l}\text { cell projection } \\
(\mathrm{GO}: 0042995)(\uparrow, P<0.05)\end{array}$ \\
\hline & & $\begin{array}{l}\text { midbody } \\
(\mathrm{GO}: 0030496)(\uparrow, P<0.05)\end{array}$ \\
\hline
\end{tabular}

\section{Biological processes}

response to organic substance

(GO:0010033) $(\uparrow, P<0.05)$

regulation of metabolic process

(GO:0019222) $\left(\uparrow, P<10^{-3}\right)$

regulation of catalytic activity

(GO:0050790) $\left(\uparrow, P<10^{-2}\right)$

regulation of cellular process

(GO:0050794) $\left(\uparrow, P<10^{-3}\right)$

regulation of cellular component organization (GO:0051128)

$(\uparrow, P<0.05)$

nucleobase, nucleoside, nucleotide and nucleic acid

metabolic process

(GO:0006139) $\left(\uparrow, P<10^{-2}\right)$

macromolecule biosynthetic process (GO:0009059) $\left(\uparrow, P<10^{-3}\right)$

gene expression

(GO:0010467) $\left(\uparrow, P<10^{-2}\right)$

cellular biosynthetic process

(GO:0044249) $\left(\uparrow, P<10^{-4}\right)$

programmed cell death

(GO:0012501) $\left(\uparrow, P<10^{-2}\right)$ transferase activity, transferring phosphorus-containing groups $0: 0016772)(\uparrow, P<10$

$\left(\uparrow, P<10^{-4}\right)$

protein domain specific binding

(GO:0022891) $\left(\uparrow, P<10^{-4}\right)$

cytoskeletal protein binding

(GO:0005543) $\left(\uparrow, P<10^{-2}\right.$

identical protein binding

$P<10^{-8}$

heat shock protein binding

(GO:0031072) $(\uparrow, P<0.05)$

oxidoreductase activity, acting on peroxide as acceptor

extracellular matrix

(GO:0031012) $\left(\uparrow, P<10^{-3}\right)$

(GO:0005615) $\left(\uparrow, P<10^{-8}\right)$

endomembrane system

GO:0012505) $\left(\uparrow, P<10^{-3}\right)$

cell surface

(GO:0009986) $\left(\uparrow, P<10^{-4}\right)$

cell projection

midbody

(GO:0030496) $(\uparrow, P<0.05)$

response to organic substance

(GO:0010033) $\left(\uparrow, P<10^{-5}\right)$

lipid metabolic process

(GO:0006629) $\left(\uparrow, P<10^{-6}\right)$

defense response

(GO:0006952) $\left(\uparrow, P<10^{-3}\right)$

response to other organism

(GO:0051707) $(\uparrow, P<0.05)$

carbohydrate metabolic process

(GO:0005975) $(\uparrow, P<0.05)$

response to drug

(GO:0042493) $\left(\uparrow, P<10^{-3}\right)$

cell-cell signaling

(GO:0007267) $\left(\uparrow, P<10^{-2}\right)$

cytoskeleton organization

(GO:0007010) $\left(\uparrow, P<10^{-3}\right)$

regulation of developmental process (GO:0050793) $\left(\uparrow, P<10^{-4}\right)$

regulation of immune system process (GO:0002682) $\left(\uparrow, P<10^{-4}\right)$

\footnotetext{
${ }^{\text {a }}$ Specifically enriched GO terms are highlighted in bold fonts

b The symbol $\uparrow$ or $\downarrow$ represents the enrichment status of "enriched" or "depleted" of the GO term, respectively.

${ }^{c} P$ values were Bonferroni-corrected for multiple tests
} 
$\operatorname{Exp} D_{1-\mathrm{r}}$, which represents the dissimilarity in expression profile, was calculated by 1-Pearson's correlation coefficient of the expression signals of the six tissues. $E x p D_{\text {Euc }}$, which represents the summed difference in expression levels, was calculated by the Euclidean distance of the expression signals of the six tissues. CTCF-binding sites identified by ChIP-seq experiments [25] in 13 non-cancerous human cells (Table S5 in Additional file 1) were obtained from broadPeak data deposited as GSE30263 at NCBI GEO. We generated two sets of CTCF-binding sites. The number of overlapping CTCF-binding sites, which are CTCF-binding regions present in all examined cell types (Table S5 in Additional file 1), was determined using BEDTools [39]. The number of joint CTCF-binding sites, the union of CTCF-binding sites from all cell types, was determined using a custom Perl script. Enrichment analyses on GO terms were performed using FatiGO [40]. Partial correlation analyses were performed using modules of the "ppcor" package (v.1.0) [41] for R (http:// www.r-project.org/).

\section{Additional material}

Additional file 1: Supplementary tables S1-S5.

Competing interests

The authors declare that they have no competing interests.

\section{Authors' contributions}

B.-Y.L. designed research; B.-Y.L. and A.Y.C. performed research; A.Y.C. analyzed data; B.-Y.L. wrote the paper. All authors read and approved the final manuscript.

\section{Acknowledgment and funding}

This work was supported by intramural funding from the National Health Research Institutes, Taiwan, and research grant (NSC 101-2311-B-400-001MY3) from the National Science Council, Taiwan, to B.-Y.L.

\section{Declaration}

Publication of this article was funded by the intramural funding of National Health Research Institutes, Taiwan, and research grant (grant number NSC 101-2311-B-400-001-MY3) from the National Science Council, Taiwan, to BYL. This article has been published as part of BMC Genomics Volume 15 Supplement 1, 2014: Selected articles from the Twelfth Asia Pacific Bioinformatics Conference (APBC 2014): Genomics. The full contents of the supplement are available online at http://www.biomedcentral.com/ bmcgenomics/supplements/15/S1.

Published: 24 January 2014

\section{References}

1. Ohno S: Evolution by gene duplication New York Springer-Verlag; 1970.

2. Zhang J: Evolution by gene duplication: an update. Trends Ecol Evol 2003, 18:292-298.

3. Fan $C$, Chen $Y$, Long M: Recurrent tandem gene duplication gave rise to functionally divergent genes in Drosophila. Mol Biol Evol 2008, 25:1451-1458.

4. Shoja V, Zhang L: A roadmap of tandemly arrayed genes in the genomes of human, mouse, and rat. Mol Biol Evol 2006, 23:2134-2141.

5. Lynch M, Conery JS: The evolutionary fate and consequences of duplicate genes. Science 2000, 290:1151-1155.
6. Qian W, Liao B-Y, Chang AY, Zhang J: Maintenance of duplicate genes and their functional redundancy by reduced expression. Trends Genet 2010, 26:425-430.

7. Li W-H, Yang J, Gu X: Expression divergence between duplicate genes. Trends Genet 2005, 21:602-607.

8. Liao B-Y, Zhang J: Coexpression of linked genes in Mammalian genomes is generally disadvantageous. Mol Biol Evol 2008, 25:1555-1565.

9. Li SS, O'Brien DA, Hou EW, Versola J, Rockett DL, Eddy EM: Differential activity and synthesis of lactate dehydrogenase isozymes A (muscle), B (heart), and C (testis) in mouse spermatogenic cells. Biology of reproduction 1989, 40:173-180.

10. Carroll SB: Homeotic genes and the evolution of arthropods and chordates. Nature 1995, 376:479-485.

11. Cuddapah S, Jothi R, Schones DE, Roh TY, Cui K, Zhao K: Global analysis of the insulator binding protein CTCF in chromatin barrier regions reveals demarcation of active and repressive domains. Genome Res 2009, 19:24-32.

12. Valenzuela L, Kamakaka RT: Chromatin insulators. Annu Rev Genet 2006, 40:107-138.

13. Bell AC, West AG, Felsenfeld G: The protein CTCF is required for the enhancer blocking activity of vertebrate insulators. Cell 1999, 98:387-396.

14. Handoko L, Xu H, Li G, Ngan CY, Chew E, Schnapp M, Lee CW, Ye C, Ping JL, Mulawadi F, et al: CTCF-mediated functional chromatin interactome in pluripotent cells. Nat Genet 2011, 43:630-638.

15. Zou Y, Su Z, Huang W, Gu X: Histone modification pattern evolution after yeast gene duplication. BMC Evol Biol 2012, 12:111.

16. Berke L, Sanchez-Perez GF, Snel B: Contribution of the epigenetic mark H3K27me3 to functional divergence after whole genome duplication in Arabidopsis. Genome Biol 2012, 13:R94.

17. Chang AY, Liao B-Y: DNA methylation rebalances gene dosage after Mammalian gene duplications. Mol Biol Evol 2012, 29:133-144.

18. Lercher MJ, Blumenthal T, Hurst LD: Coexpression of neighboring genes in Caenorhabditis elegans is mostly due to operons and duplicate genes. Genome Res 2003, 13:238-243.

19. Hurst LD, Pal C, Lercher MJ: The evolutionary dynamics of eukaryotic gene order. Nat Rev Genet 2004, 5:299-310.

20. Brawand D, Soumillon M, Necsulea A, Julien P, Csardi G, Harrigan P, Weier M, Liechti A, Aximu-Petri A, Kircher M, et al: The evolution of gene expression levels in mammalian organs. Nature 2011, 478:343-348.

21. Glazko G, Mushegian A: Measuring gene expression divergence: the distance to keep. Biology direct 2010, 5:51

22. Bernstein BE, Birney E, Dunham I, Green ED, Gunter C, Snyder M: An integrated encyclopedia of DNA elements in the human genome. Nature 2012, 489:57-74

23. Herold M, Bartkuhn M, Renkawitz R: CTCF: insights into insulator function during development. Development 2012, 139:1045-1057.

24. Jones PA, Takai D: The role of DNA methylation in mammalian epigenetics. Science 2001, 293:1068-1070.

25. Wang H, Maurano MT, Qu H, Varley KE, Gertz J, Pauli F, Lee K, Canfield T, Weaver M, Sandstrom R, et al: Widespread plasticity in CTCF occupancy linked to DNA methylation. Genome Res 2012, 22:1680-1688.

26. Hughes AL: Adaptive evolution of genes and genomes New York: Oxford University Press; 1999.

27. Su Z, Wang J, Yu J, Huang X, Gu X: Evolution of alternative splicing after gene duplication. Genome Res 2006, 16:182-189.

28. Yandell M, Mungall CJ, Smith C, Prochnik S, Kaminker J, Hartzell G, Lewis S, Rubin GM: Large-scale trends in the evolution of gene structures within 11 animal genomes. PLoS Comput Biol 2006, 2:113-125.

29. Woo YH, Li W-H: Gene clustering pattern, promoter architecture, and gene expression stability in eukaryotic genomes. Proc Natl Acad Sci USA 2011, 108:3306-3311.

30. Shoja V, Murali TM, Zhang L: Expression divergence of tandemly arrayed genes in human and mouse. Comparative and functional genomics 2007, 60964.

31. Caron $H$, van Schaik $B$, van der Mee $M$, Baas F, Riggins $G$, van Sluis $P$, Hermus MC, van Asperen R, Boon K, Voute PA, et al: The human transcriptome map: clustering of highly expressed genes in chromosomal domains. Science 2001, 291:1289-1292.

32. Moon H, Filippova G, Loukinov D, Pugacheva E, Chen Q, Smith ST, Munhall A, Grewe B, Bartkuhn M, Arnold R, et al: CTCF is conserved from Drosophila to humans and confers enhancer blocking of the Fab-8 insulator. Embo Rep 2005, 6:165-170. 
33. Ni X, Zhang YE, Negre N, Chen S, Long M, White KP: Adaptive evolution and the birth of CTCF binding sites in the Drosophila genome. PLOS Biol 2012, 10:e1001420

34. Durinck S, Moreau Y, Kasprzyk A, Davis S, De Moor B, Brazma A, Huber W: BioMart and Bioconductor: a powerful link between biological databases and microarray data analysis. Bioinformatics 2005, 21:3439-3440.

35. Yang Z: PAML 4: phylogenetic analysis by maximum likelihood. $\mathrm{Mol}$ Biol Evol 2007, 24:1586-1591.

36. Vilella AJ, Severin J, Ureta-Vidal A, Heng L, Durbin R, Birney E: EnsemblCompara GeneTrees: Complete, duplication-aware phylogenetic trees in vertebrates. Genome Res 2009, 19:327-335.

37. Chang TY, Liao BY: Flagellated algae protein evolution suggests the prevalence of lineage-specific rules governing evolutionary rates of eukaryotic proteins. Genome Biol Evol 2013, 5:913-922.

38. Matsuo K, Clay O, Takahashi T, Silke J, Schaffner W: Evidence for erosion of mouse CpG islands during mammalian evolution. Somatic cell and molecular genetics 1993, 19:543-555.

39. Quinlan AR, Hall IM: BEDTools: a flexible suite of utilities for comparing genomic features. Bioinformatics 2010, 26:841-842.

40. Al-Shahrour F, Diaz-Uriarte R, Dopazo J: FatiGO: a web tool for finding significant associations of Gene Ontology terms with groups of genes. Bioinformatics 2004, 20:578-580.

41. Kim SH, Yi SV: Understanding relationship between sequence and functional evolution in yeast proteins. Genetica 2007, 131:151-156.

doi:10.1186/1471-2164-15-S1-S8

Cite this article as: Liao and Chang: Accumulation of CTCF-binding sites drives expression divergence between tandemly duplicated genes in humans. BMC Genomics 2014 15(Suppl 1):S8.

\section{Submit your next manuscript to BioMed Central and take full advantage of:}

- Convenient online submission

- Thorough peer review

- No space constraints or color figure charges

- Immediate publication on acceptance

- Inclusion in PubMed, CAS, Scopus and Google Scholar

- Research which is freely available for redistribution

Submit your manuscript at www.biomedcentral com/submit 